\title{
Da aplicação do Diretório Pombalino ao Estado do Brasil: povos indígenas e políticas linguísticas no século XVIII
}

\author{
Pedro Daniel dos Santos Souza* \\ Universidade do Estado da Babia, Salvador, Bahia, Brasil \\ Tânia Lobo** \\ Universidade Federal da Babia, Salvador, Bahia, Brasil
}

\begin{abstract}
Resumo: O Directorio, que se deve observar nas povoaçoens dos indios do Pará, e Maranhaõ em quanto Sua Magestade naõ mandar o contrario - simplesmente conhecido como Diretório pombalino ou Diretório dos indios - instituiu uma política de proibição do uso das línguas indígenas e, em particular, da chamada língua geral como um dos principais objetivos do processo de "civilização" dos índios, o que não só resultou em perdas linguísticas irreparáveis, como também em mudanças linguístico-culturais que, associadas a outros fatores relevantes, definiram o rumo do Brasil como país majoritariamente falante da língua portuguesa. Criado, em 1757, para ser aplicado ao Estado do Grão-Pará e Maranhão, a partir de 1758, foi também direcionado à outra colônia portuguesa na América, o Estado do Brasil, até finalmente suas disposições serem revogadas por meio da Carta Régia de 12 de maio de 1798. Neste artigo, apresentamos e discutimos os principais documentos e o trâmite burocrático referentes ao início da aplicação do Diretório no Estado do Brasil, destacando o papel central atribuído pelo Parecer exarado pelo Tribunal Especial do Conselho Ultramarino aos escrivães das câmaras como agentes de letramento indígena.
\end{abstract}

Palavras chave: Brasil Colônia. Populações Indígenas. Políticas linguísticas. Diretório dos índios.

\begin{abstract}
The Directory, which should be observed in the settlements of the Indians of Pará, and Maranbao, inasmuch as His Majesty did not send the opposite - simply known as the Pombaline Directory or Directory of the Indians instituted a policy prohibiting the use of indigenous languages and, in particular, of the so-called general language as one of the main objectives of the process of "civilization" of the Indians, which not only resulted in irreparable linguistic losses, but also in linguisticcultural changes that, along with other relevant factors, defined Brazil as a country mostly speaking the Portuguese language. Created in 1757 to be applied to the State of Grão-Pará and Maranhão, from 1758, it was also directed to the other Portuguese colony in America, the State of Brazil, until finally its provisions were revoked by the Royal Charter of 12 Of May of 1798. In this article, we present and discuss the main documents and the bureaucratic process concerning the beginning of the application of the Directory in the State of Brazil, highlighting the central role assigned by the Opinion of the Special Court of the Overseas Council to the clerks of the chambers as agents of indigenous literacy.
\end{abstract}

Keywords: Brazil Colonia. Indigenous Populations. Language policies. Directory of Indians.

\section{SOBRE O DIRETÓRIO POMBALINO E SUA POLÍTICA LINGUÍSTICA}

Criado, em 1757, por Francisco Xavier de Mendonça Furtado, Governador e Capitão General do Estado do Grão-Pará e Maranhão, o Directorio, que se deve observar nas povoaçoens dos indios do Pará, e Maranhaõ em quanto Sua Magestade naõ mandar o contrario, passou, a partir de 1758, a ser direcionado para o Estado do Brasil, conforme determinado por Sebastião José de Carvalho e Melo, o Marquês de Pombal, até sua revogação por meio da Carta Régia de 12 de maio de 1798. Lei colonial que se tornou conhecida como Diretório pombalino ou Diretório dos indios, entre as diversas questões abordadas ao longo dos seus noventa e cinco parágrafos,

\footnotetext{
* Professor da Universidade do Estado da Bahia, doutorando em Língua e Cultura na Universidade Federal da Bahia (UFBA), com bolsa de pesquisa da Fundação de Apoio à Pesquisa do Estado da Bahia (FAPESB). E-mail: pdsouza.uneb.br. ** Professora da Universidade Federal da Bahia, doutora em Filologia e Língua Portuguesa (USP). E-mail: tanlobo@gmail.com.
} 
chamam a atenção daqueles que se debruçam sobre a história social linguística do Brasil as tratadas nos parágrafos seis, sete e oito, na medida em que instituem a política de proibição do uso de quaisquer línguas indígenas e, em particular, da chamada língua geral ${ }^{1}$, e planejam fazê-lo através do ensino escolarizado da língua portuguesa às crianças indígenas.

No seu parágrafo terceiro, o referido documento afirma que as "paternais providências" do rei se dirigiam unicamente a cristianizar e civilizar os índios, para que, retirados do estado de barbaridade e rusticidade a que se achavam reduzidos em pleno século XVIII, como se ainda vivessem nos incultos sertões, a despeito de mais de dois séculos do início da colonização portuguesa, pudessem ser úteis a si mesmos, aos moradores e ao Estado.

Feitas as necessárias e devidas ressalvas, o Diretório, como gênero textual, pode ser inscrito entre os chamados manuais civilizatórios que passaram a adestrar o comportamento humano nas sociedades modernas europeias e também nos seus domínios coloniais. Como tal, instituiu um conjunto de ações de um programa mínimo, a ser executado com "prudência", "suavidade" e "brandura", para fazer dos índios brasileiros seres civilizados. Tais ações seriam:

- torná-los cristãos;

- torná-los falantes da língua portuguesa, escolarizando-os - inclusive as meninas -, se isto fosse necessário para alcançar tal fim;

- tratar os que ocupavam postos relevantes, tais como os de principais, sargentosmores, capitães, vereadores, juízes ordinários e outros ofícios com as honras e os privilégios competentes aos seus postos (honras e privilégios extensíveis às suas famílias);

- não permitir que dali por diante fossem tratados por negros nem que entre si usassem de tal tratamento, para que compreendessem que não lhes competia a vileza do referido nome;

- dar-lhes sobrenomes e também os apelidos das famílias portuguesas;

- fazê-los fabricar as suas casas à imitação das casas dos brancos, para que as famílias vivessem separadas;

- fazê-los abandonar o vício abominável, dominante e universal da ebriedade;

- obrigá-los, por meio do seu trabalho, a adquirir vestuário e a vestir-se à proporção da qualidade das suas pessoas e das graduações dos seus postos, devendo o vício da desnudez ser desterrado especialmente das mulheres;

- fazê-los cultivar suas terras, não apenas para saírem do abatimento e da pobreza, mas também para dar cabo de outro vício, o da ociosidade, acrescendo-se que aqueles que mais rendessem no trabalho teriam preferência nas honras e privilégios concedidos pelo rei;

- por fim, concorreria também para a civilidade dos índios a introdução de brancos em suas terras.

Posteriormente aos parágrafos de apresentação das ações civilizatórias propriamente ditas, o texto do Diretório trata detalhadamente de questões relativas ao cultivo da terra pelos índios (do parágrafo $19^{\circ}$ ao $34^{\circ}$ ), ao comércio dos produtos das suas plantações (do parágrafo $35^{\circ}$ ao $58^{\circ}$ ), à forma como se deveria fazer a distribuição dos índios pelos moradores do Estado (do parágrafo $59^{\circ}$ ao $73^{\circ}$ ), à construção de casas da câmara e cadeias públicas nas

${ }^{1}$ Embora compreendamos que a expressão "língua geral" recobre uma série de conceitos e concepções, sendo, portanto, polissêmica, não nos ateremos a esta discussão no presente momento. Assim, fazemos uso da expressão "língua geral" no singular, considerando a forma como se apresenta nas fontes documentais investigadas, a despeito da distinção estabelecida por Rodrigues (1986) entre a língua geral paulista e a língua geral amazônica. 
vilas (do parágrafo $74^{\circ}$ ), ao envio de mapas dos índios ausentes das suas povoações, assim como dos que se achassem nos matos ou nas casas dos moradores, para o exame da causa da sua deserção e para a sua restituição às povoações (parágrafo $75^{\circ}$ ), ao descimento dos índios (do parágrafo $76^{\circ}$ ao $79^{\circ}$ ), às precauções que deveriam ser tomadas no que diz respeito à introdução de brancos nas terras indígenas (do parágrafo $80^{\circ}$ ao $89^{\circ}$ ), às penas prevista para os casos de negligência ou malícia por parte dos que deveriam zelar pelo cumprimento das disposições do Diretório (parágrafo $92^{\circ}$ ) e, finalmente ao reforço à recomendação do uso de "prudência", "suavidade" e "brandura" na execução de todas as ordens (do parágrafo $93^{\circ}$ ao $\left.95^{\circ}\right)$.

Para a execução de tais ordens, instituiu o próprio Diretório a figura do Diretor de indios, a ser nomeado pelo Governador e Capitão Geral do Estado para cada aldeamento indígena tornado vila, pessoa que deveria ser dotada "de bons costumes, zelo, prudência, verdade, ciência da língua e de todos os mais requisitos necessários para poder dirigir com acerto os referidos índios". Vale dizer que, pelo Alvará de 7 de julho 1755, de dois anos, portanto, antes do Diretório, o rei de Portugal tinha abolido a administração temporal exercida pelos padres regulares ${ }^{2}$ sobre os índios das aldeias do Estado do Grão-Pará e Maranhão, mandando governá-las por seus respectivos principais, os quais, contudo, foram julgados pelo Diretório inaptos para fazê-lo, por serem considerados lastimavelmente rústicos, devido à ignorância em que teriam sido educados. E assim sendo, deveriam ficar os índios sob a tutela de um Diretor.

Essa intenção de "civilizar", como mecanismo de uma política de assimilação, integração dos povos indígenas à sociedade brasileira em formação, deveria ter estado, em primeiro plano, fundamentada na imposição da língua do conquistador aos povos conquistados, o que, conforme afirmado no próprio Diretório, não teria sido observado pelos primeiros colonizadores portugueses, que destoavam, assim, dos demais povos colonizadores:

Sempre foi maxima inalteravelmente praticada em | todas as Naçoens, que conquistáraõ novos Dominios, intro- $\mid$ duzir logo nos Póvos conquistados o seu proprio idiôma, por | ser indisputavel, que este he hum dos meios mais efficazes para | desterrar dos Póvos rusticos a barbaridade dos seus antigos | costumes; e ter mostrado a experiencia, que ao mesmo passo, | que se intoduz nelles o uso da Lingua do Principe, que os $\mid$ conquistou, se lhes radîca tambem o affecto, a veneraçaõ, e | a obediencia ao mesmo Principe. Observando pois todas | as Naçoens polîdas do Mundo este prudente, e sólido systema, | nesta Conquista se praticou tanto pelo contrário (...) (Directorio, 1758, p. 3, parágrafo 6) ${ }^{3}$

O papel que teria desempenhado o Diretório dos índios no sentido de promover a generalização da língua portuguesa no Brasil se inscreve entre as muitas questões que devem ser abordadas no âmbito da escrita de uma história social linguística do Brasil. Quanto a esta escrita, considerando a produção historiográfica brasileira dominante, dois esquecimentos acabaram sendo gestados e até mesmo difundidos na sociedade em geral, extrapolando os meios acadêmicos: primeiro, o esquecimento que gerou a construção de uma unidade territorial e política da nação brasileira já a partir de 1500, apagando a memória de que havia duas colônias na América portuguesa, cada uma autônoma em relação à outra - o Estado do Brasil e o Estado do Grão-Pará e Maranhão - e que a referida unidade só vai se consolidar com a adesão do Grão-Pará e Maranhão ao Brasil, em agosto de 1823, praticamente um ano após a independência proclamada em 7 de setembro de 1822; segundo, o esquecimento que

2 Os que seguem as regras de uma determinada Ordem e se diferenciam dos chamados padres seculares, vinculados diretamente ao Vaticano. Tais padre não eram apenas os jesuítas, pois havia aldeias administradas por padres de outras Ordens, embora a atuação da Companhia de Jesus tenha predominado largamente.

3 A edição do Diretório dos indios, bem como das demais fontes documentais citadas ao longo do artigo, seguiu as normas de edição de textos do Projeto Para a História do Português Brasileiro (PHPB), com alterações em função da natureza própria de cada documento. Para o Diretório dos índios, consideramos o fac-símile publicado em Almeida (1997). 
gerou a construção de uma unidade linguística desde 1500, tomando o português como a única língua da colonização e desconsiderando a ampla difusão das línguas gerais de base indígena, hegemônicas, durante quase todo o período colonial, em vastos espaços, além do próprio esquecimento do quadro diversificado das línguas indígenas aqui faladas quando da chegada dos europeus, bem como das línguas transplantadas da África com o tráfico de escravizados (FREIRE, 2004).

Atestando a relevância desse papel e não perdendo de vista a distinta história linguística das duas colônias portuguesas na América, no presente texto, direcionamos nosso olhar ao trâmite burocrático que estende a política linguística implantada pelo Diretório de Pombal ao Estado do Grão-Pará e Maranhão para o Estado do Brasil, trazendo à luz os documentos relevantes e analisando mais detidamente o principal deles, a saber: o Parecer do Conselho Ultramarino da Bahia sobre os paragraphos do Directorio para regimen dos Indios das Aldeias das Capitanias do Pará e Maranbão, approvado por Alvará regio de 17 de agosto de 1758 e que podiam ser applicaveis aos Indios do Estado do Brazil, datado de 17 de maio de 1759.

Marcadamente a partir do século XVIII, a política linguística do Estado português e, no século XIX, com a Independência, do Estado brasileiro, sempre foi a de reduzir o número de línguas, num processo de glotocídio através de "deslocamentos linguísticos", caracterizados por substituição das línguas indígenas, no caso aqui em pauta, pela língua portuguesa. É só a partir da Constituição Federal de 1988, portanto, há apenas pouco mais de 25 anos, que, segundo Morello (2012, p. 13-14), se poderá falar de um "reposicionamento do Estado brasileiro diante da diversidade linguística". Diz a autora:

\begin{abstract}
No Brasil, o primeiro avanço notável se deu com a Constituição Federal de 1988, que reconheceu aos indígenas o direito à cidadania, à sua cultura e à sua língua. No entanto, as inúmeras línguas de imigrantes (Talian, Italiano, Alemão, Ucraniano, Polonês...), os crioulos (Karipuna e Galibi-Marworno), as línguas de sinais (LIBRAS e Kaapor) e as afro-brasileiras permaneceram no silenciamento [...]. Este panorama foi modificado, em nível nacional, apenas com a implementação da política de Reconhecimento e Registro de todas as línguas praticadas no Brasil através do Inventário Nacional da Diversidade Linguística do Brasil (INDL), instituído pelo Decreto no 7.387/2010. De acordo com o relatório do Grupo de Trabalho da Diversidade Linguística (GTDL), a política de Reconhecimento e Registro contempla todas as línguas que "tenham relevância para a memória e identidade dos grupos que compõem a sociedade Brasileira, sejam veículo de transmissão cultural e faladas no território nacional há pelo menos três gerações (ou 75 anos)" (Relatório do GTDL, 2007, p. 11).
\end{abstract}

A lei no 10.436, de 20 de abril de 2002, como é sabido, regulamentou o uso da Língua Brasileira de Sinais (LIBRAS) na educação e reconheceu direitos fundamentais das comunidades surdas, tornando, assim, o Brasil, em toda a sua extensão territorial, um país oficialmente bilíngue.

Apesar de, no país, destaca mais uma vez Morello (2012, p. 12), não haver, além do português e da LIBRAS, nenhuma outra língua de abrangência nacional ou mesmo regional, há um conjunto expressivo de municípios onde se falam majoritariamente línguas indígenas ou línguas da imigração, o que os converte em "instâncias potentes para a gestão de línguas". Foi com base nesta visão que se iniciou, a partir do ano de 2002 e do município mais plurilíngue do Brasil - o munícipio amazônico de São Gabriel da Cachoeira -, a política de cooficialização de línguas em âmbito municipal, uma iniciativa inovadora no campo das políticas linguísticas no país. Passados quinze anos, quinze outros municípios de sete estados brasileiros têm línguas cooficiais, sendo sete línguas indígenas - o nheengatu, o baniwa, o 
tukano, o guarani, o xerente, o macuxi e o wapichana - e quatro línguas de imigração - o pomerano, o talian, o hunsrükisch e o alemão.

Podemos considerar, portanto, que a história social linguística do Brasil até muito recentemente refletiu sucessivas políticas linguísticas homogeneizadoras e repressivas, que resultaram num processo marcado pela morte de línguas. Nessa trajetória, podemos entrever as consequências da implantação do projeto pombalino de forma mais expressiva a partir do excerto que reproduzimos abaixo:

Observando pois todas | as Naçoens polîdas do Mundo este prudente, e sólido systema, | nesta Conquista se praticou tanto pelo contrário, que só cuidá- | raõ os primeiros Conquistadores estabelecer nella o uso da | Lingua, que chamaráõ geral; invençaõ verdadeiramente abo-| minavel, e diabólica, para que privados os Indios de todos | aquelles meios, que os podiaõ civilizar, permanecessem na | rustica, e barbara sujeiçaõ, em que até agora se conservávaõ. Para desterrar este perniciosissimo abuso, será hum dos prin-| cipáes cuidados dos Directores, estabelecer nas suas respecti-| vas Povoaçoens o uso da Lingua Portugueza, naõ consen-| tindo por modo algum, que os Meninos, e Meninas, que | pertencerem ás Escólas, e todos aquelles Indios, que forem | capazes de instrucçaõ nesta materia, usem da Lingua propria | das suas Naçoens, ou da chamada geral; mas unicamente da | Portugueza, na fórma, que Sua Magestade tem recomenda- $\mid$ do em repetidas Ordens, que até agora se naõ observáraõ com | total ruina Espiritual, e Temporal do Estado (Directorio, 1758, p. 3-4, parágrafo 6 , grifo nosso).

Explicitamente, o Diretório apresenta uma política linguística que prevê o glotocídio das línguas indígenas, aqui representadas pela "língua própria das suas nações, ou [pela] chamada geral" - tida esta última como "invenção verdadeiramente abominável e diabólica" -, em favor da língua portuguesa, tomada como a língua de civilização, o que acabou por fortalecer o seu caráter majoritário e hegemônico. Ademais, o Marquês de Pombal não acreditava nos métodos de conversão e catequização utilizados pelos jesuítas, os quais teriam feito com que o real processo de civilização pela língua tivesse um atraso significativo, ou seja, os jesuítas teriam perdido tempo numa tentativa frustrada de civilizar os índios, além de sua permissividade ter "privado" as populações indígenas de se civilizarem, mantendo-as no estado de "rústica e bárbara sujeição".

Outra questão evidenciada no Diretório diz respeito à associação entre ensino da leitura e da escrita à catequese, destacando a possibilidade de aprendizagem dos dogmas da fé cristã e da língua portuguesa como ações integradas. Assim, determina a criação de escolas públicas não só para meninos, mas também para meninas indígenas, fugindo neste aspecto ao que era predominante ainda no século XVIII, ou seja, a oferta de ensino escolarizado público quase exclusivamente para crianças do sexo masculino. A estratégia de abertura de duas escolas para a implementação da política pombalina está apresentada no trecho abaixo:

E como esta determinaçaõ he a base fundamental da | Civilidade, que se pretende, haverá em todas as Povoaçoens | duas Escólas pûblicas, huma para os Meninos, na qual se lhes | ensine a Doutrina Christãa, a ler, escrever, e contar na fór- $\mid$ ma, que se pratíca em todas as Escólas das Naçoens civiliza- | das; e outra para as Meninas, na qual, álem de serem instrui- | das na Doutrina Christãa, se lhes ensinará a ler, escrever, fi- $\mid$ ar, fazer renda, cultura, e todos os mais ministérios pro- $\mid$ prios daquelle sexo. (Directorio, 1758, p. 4, parágrafo 7)

Dessa forma, além de expressar uma política linguística quanto à oficialização da língua portuguesa como língua do ensino, o Diretório traz em seu bojo o que tem sido chamado de planejamento linguístico, ou seja, os meios de aplicação da política linguística (CALVET, 2007). Com isso, não só evidenciamos uma orientação que prevê a inserção das populações indígenas em práticas de uma cultura escrita em língua portuguesa, mas ainda as suas consequências materializadas nos glotocídios linguísticos testemunhados ao longo do processo de formação da sociedade brasileira, por meio do processo de escolarização, ou 
seja, da emergência, no Brasil colonial, da escola para índios e não de índios, na medida em que esses espaços institucionais, centrados na catequese, ignoraram as instituições educativas indígenas e executaram uma política destinada a desarticular a identidade das etnias, discriminando suas línguas e culturas, que foram desconsideradas no processo educativo.

Vale destacar que, com vistas a não cairmos na acusação de um suposto anacronismo, embora os conceitos de língua oficial e de políticas linguísticas ainda não existissem no período que está sendo abordado, as práticas e métodos que regiam o uso das línguas nesse período revelam ações políticas organizadas que agiram diretamente sobre o multilinguismo generalizado dos primeiros séculos da colonização. Sendo assim, podemos considerar que, avant la lettre, os portugueses instituíram políticas linguísticas na América portuguesa, objetivando a consolidação de uma língua única e, consequentemente, reforçando as relações entre unidade linguística e nacionalidade, aproximação que será retomada em momentos diversos.

Para as escolas públicas indicadas para serem criadas pelo Diretório, previa-se um mestre para meninos e uma mestra para meninas, os quais teriam que ser dotados de "bons costumes, prudência e capacidade", para que assim pudessem desempenhar bem as suas obrigações, que, como se viu acima, se distinguiam conforme o sexo do educando, já que as meninas, "além de serem instruídas na doutrina cristã, e de aprender a ler, escrever", também deveriam aprender "a fiar, fazer renda, cultura, e todos os mais ministérios próprios daquele sexo". Os meninos e meninas deveriam ser educados separadamente; só na falta de mestras, as meninas, até os dez anos, poderiam ser ensinadas juntamente com os meninos:

Para a subsistencia das sobreditas Escólas, e de hum | Mestre, e huma Mestra, que devem ser Pessoas dotadas de | bons costumes, prudência, e capacidade, de sorte, que possaõ | desempenhar as importantes obrigaçoens de seus empregos; | [...] No caso porém de naõ haver nas | Povoaçoens Pessoa alguma, que possa ser Mestra de Meninas, | poderáõ estas até á idade de dez annos serem instruidas na Es-| cóla dos Meninos, onde aprederáõ a Doutrina Christãa, a | ler, e escrever, para que juntamente com as infalliveis verda- | des da nossa Sagrada Religiaõ adquiraõ com maior facilida- $\mid$ de o uso da Lingua Portugueza. (Directorio, 1758, parágrafo, p. 4)

Aqui cabe um parêntese relevante e que diz respeito à mudança, ao longo do século XVIII, na própria concepção do que seria uma "mestra". Como destacam diversos historiadores da cultura escrita, no Antigo Regime, não só poucas mulheres eram alfabetizadas, como as que o eram podiam dominar a leitura, mas não saber escrever. A questão é tratada, por exemplo, por Marquilhas (2000, p. 118), ao dizer que a educação feminina "não incluía, à partida, a transmissão da capacidade da escrita" e chamar a atenção para o fato de que "Rafael Bluteau dizia no Vocabulario Portuguez, e Latino que o conceito de Mestra era o de Mulher que ensina meninas a ler, cozer, etc., sem referência explícita ao ensino da escrita".

Como já dissemos, vemos materializadas, no Diretório, duas faces da mesma moeda: a política linguística e o planejamento. É a implementação deste que garante o sucesso daquela, uma vez que se configura como sua aplicação (CALVET, 2007). Na proposta de Pombal, evidencia-se uma preocupação com a escola para índios, e não de índios como também já dissemos, com vistas a garantir a execução da política linguística. Nessa perspectiva, a repressão às línguas indígenas e à língua geral configurou-se como uma estratégia concernente ao planejamento linguístico que tornou o projeto colonizador possível e aplicável, atendendo, portanto, aos interesses da Coroa portuguesa. Além disso, as políticas linguísticas executadas no período colonial deixaram suas marcas na história linguística do Brasil, dado o fato de que a cultura do monolinguismo continua perdurando, bem como o preconceito linguístico relativamente às variantes do português brasileiro mais 
significativamente marcadas por uma história de contato quer com línguas indígenas, quer com línguas africanas.

Evidentemente, inúmeras outras questões podem ser levantadas, bem como novos direcionamentos para uma compreensão da apropriação da escrita pelos povos indígenas, na medida em que aprender a ler e escrever o português também podia constituir-se como um "instrumento eficaz para alguns deles, sobretudo lideranças, reivindicarem suas mercês ao Rei em moldes bem portugueses" (ALMEIDA, 2010, p. 91). Sendo assim, no seu processo de reconfiguração identitária, essas populações passaram a utilizar das práticas culturais e políticas lusitanas como forma de resistência e/ou sobrevivência, "integrando-se" à sociedade colonial em formação e, consequentemente, inserindo-se nas práticas de cultura escrita em língua portuguesa, o que contribuiu, significativamente, para a implementação da política linguística pombalina e os glotocídios testemunhados pelo devir da história.

A par das reflexões aqui sinteticamente apresentadas, que tomaram como fio condutor a análise dos parágrafos seis, sete e oito do Diretório pombalino, passaremos a discutir como as questões relativas à política linguística instituída pelo Marquês de Pombal para o Estado do Grão-Pará e Maranhão serão atualizadas no Estado do Brasil.

\section{A POLÍTICA LINGUÍSTICA POMBALINA NO ESTADO DO BRASIL}

O trâmite burocrático visando à aplicação do Diretório pombalino no Estado do Brasil tem início com uma carta remetida por Thomé Joaquim da Costa Corte Real, Secretário de Estado dos Negócios da Marinha e Domínios Ultramarinos, ao Vice-Rei e Governador Geral do Brasil, D. Marcos de Noronha, o Conde dos Arcos. Abaixo, lê-se o documento transcrito na íntegra":

\section{Illustissimo e Excelentissimo Senhor}

Sua Magestade foy servido determi

nar, que nas Povoaçoens dos Indios doPará eMara

nhaõ se observasse oDirectorio, queformou Francisco

Xavier deMendoça Furtado; Governador, eCapitaõ

General daquellas Capitanias, para regimen dos diretores

Indios: oque omesmo Senhor approvou por

Alvará de 17 deAgosto do anno proximo passado,

eordena, que VossaExcelencia faça observar omesmo Directorio nas Aldeas dajusrisdiçaõ desse Estado, emto= das aquellas partes, que lhes possaõ ser applicaveis, para o que remetto aVossaExcelencia os Exemplares incluzos.

Deos guarde aVossaExcelencia Salvaterra de 15Magos a 3. deFevereiro de $\underline{1759}$.

ThomêJoachimdaCostaCorteRea ${ }^{5}$

Senhor Conde dosArcos

\footnotetext{
${ }^{4}$ Enquanto a carta se encontra preservada no Arquivo Público do Estado da Bahia Seção Colonial e Provincial, Rolo 32, Vol. 61, D. 98), no Arquivo Histórico Ultramarino, preserva-se a minuta da carta (AHU_ACL_CU_005, Cx. 139, D. 10706). Essa identificação refere-se, respectivamente, à entidade detentora (Arquivo Histórico Ultramarino), fundo documental (Conselho Ultramarino), série (Bahia - Castro Almeida), caixa e número do documento. A minuta é datada de 3 de janeiro de 1759, e a carta de 3 de fevereiro de 1759; a minuta não é assinada, mas a carta o é.

${ }^{5}$ Assinatura em caligrafia diferente do corpo do documento.
} 
No despacho, remetem-se cópias do Diretório, ordenando-se ao Vice-Rei que o fizesse observar em todas aquelas partes que pudessem ser aplicáveis nas aldeias da jurisdição do Estado do Brasil.

Conforme se pode ler na carta abaixo ${ }^{6}$, datada de $1^{\circ}$ de junho de 1759 , em resposta ao despacho de Thomé Joaquim da Costa Corte Real, o Conde dos Arcos, na condição de seu presidente, encaminhou ao Tribunal Especial do Conselho Ultramarino o Diretório, solicitando-lhe que examinasse "muito atentamente todos os pontos que nele se contêm, [para] se assentar se eram, ou não aplicáveis às povoações dos índios da jurisdição deste Estado [do Brasil]". O principal objetivo dessa carta é, pois, encaminhar ao rei de Portugal o Parecer interposto pelo Conselho Ultramarino sobre a aplicação do Diretório:

\section{Ilustissimo e Excelentissimo Senhor}

Em carta detres deFevereiro deste prezente anno me diz Vossa Excelencia, que Suamagestade havendo approvado por Alvarà de 17 deAgosto do anno proximo passado o Directorio, que formou Francisco Xavier deMendonça Furtado Governador, eCapitaõ General das Capitanias doParà, e Maranhaõ para o regimen dosIndios daquellas Povoaçoẽs, me ordenando, que o faça observar nasAldeyas dajurisdiçaõ deste Estàdo em todas aquellas partes, que lhepodessem ser applicaveis, para o que me remetteo Vossa Excelencia alguns exemplares.

Para haverde proceder comtodo o acertono que por esta carta seme determinà, me pareceo naõ só justo, mas muito conveniente fazer ver noConcelho Vltramarino, que Suamagestade mandou erigir nesteEstàdo, o predicto Directorio, para que examinandose muito attentamente todos os pontos, que nelle se contèm, se assentar, se eraõ, ou naõ applicaveis às Povoaçoens dos Indios dajurisdiçaõ desteEstàdo.

Vendo oConselho opredicto Directorio lhe pareceo devia interpor o seu parecer, que se contem no papel, que juntamente com estaserá entregue à Vossa Excelencia, ecomo nellese deduz largamente às partes, em que o mesmo Directorio pòdeser applicavel, e asem que naõ pòdeter applicaçaõ nas AldeasdoBrazil, porque os Indios, que as povôaõ, estaõ, eestiveraõ sempre em muito inferior Estàdo aos doParà, e Maranhaõ, naõ se me offerece que dizer a Vossa Excelencia, outra couza àesterespeito, senaõ que ficaõ à passar-se as Ordens necessa rias, para que em tudo aquillo, que sejulgou applicavel omesmo Directorio o haja deser sem perda detempo nasPovoaçoẽs dosIndios desteEs[tàdo] o que Vossa Excelencia farà prezente à Suamagestade para determinar o que forservido. Deos guarde avossa Excelencia Bahia, o $1^{\circ}$ deIunho de1759.

Conde D. Marcos de Noronha ${ }^{7}$

Senhor Thomè Ioaquim daCosta Corte Real

Dois pontos merecem destaque na leitura da carta: o primeiro é a informação de que o Conselho Ultramarino julgou haver pontos no Diretório que não poderiam ter aplicação nas aldeias do Estado do Brasil; o segundo é a própria justificativa apresentada para a sua não aplicação nas referidas aldeias: "porque os índios que as povoam estão, estiveram sempre em muito inferior estado aos do Pará e Maranhão".

Ao todo, o Conselho Ultramarino rejeitou 45 resoluções do Diretório, as quais faziam referência à cobrança de dízimo aos índios, à sua distribuição entre os moradores, aos descimentos, à presença de moradores brancos nas vilas de índios e à coleta das drogas do

${ }^{6}$ AHU_CU_005-01, Cx. 23, D. 4255.

${ }^{7}$ Assinatura em letra diferente da do corpo do documento. 
sertão (cf. MARCIS, 2013, p. 144). O Parecer justifica a sua rejeição ou porque tratavam de assuntos já discutidos, mas que eram objeto de consulta ao rei, ou porque tratavam de assuntos que diriam respeito apenas ao Norte. Não é propósito deste artigo discutir os pontos que foram julgados não aplicáveis, já que, em princípio, nenhum deles parece ter relevância para a história linguística do Brasil. Chamamos apenas a atenção para o fato de que a postura assumida pelo Vice-Rei despertou uma forte crítica do poder político da Metrópole, que censurou as posições de D. Marcos de Noronha sobre o Diretório e sua aplicação ${ }^{8}$.

Apesar de nem a carta que o encaminha nem o texto do Parecer esclarecerem em que consistiria o "muito inferior estado" dos índios do Estado do Brasil em face dos do Estado do Grão-Pará e Maranhão, é evidente que, aos olhos do Conde dos Arcos, estariam os do Norte mais avançados no seu processo de civilização. É provável que tal visão esteja ancorada no fato de que, diferentemente do que ocorreu nas Capitanias da Bahia e de Pernambuco, na região amazônica, a mão de obra indígena representou, nos séculos XVII e XVIII, a principal força de trabalho.

O Parecer interposto pelo Conselho Ultramarino (Cf. Anexo) é um documento datado de 19 de maio de 1759, em duas vias, e assinado, além do próprio Conde D. Marcos de Noronha, por Antônio de Azevedo Coutinho, D. José Mascarenhas Pacheco Pereira Coelho de Mello e Manuel Estevão de Vasconcellos de Almeida Barberino. Aqui, consideramos apenas a primeira via, constituída por 22 fólios, tendo a análise das suas características scriptológicas permitido levantar a hipótese - ainda a ser com mais cautela averiguada - de que o scriptor teria sido José Antônio Caldas, autor da Noticia Geral de toda esta Capitania da Babia desde o seu Descobrimento até o prezenta anno de 1759 (2015 [1759]), obra justamente dedicada ao Vice-Rei D. Marcos de Noronha, que, segundo Edison Carneiro (1969), teria servido não só de modelo, mas de inspiração para as famosas Cartas de Luís dos Santos Vilhena, embora o professor régio de grego tenha omitido não só esta, mas, de modo geral, todas as fontes em que se baseou.

Observamos, no Parecer do Conselho Ultramarino da Babia sobre os paragraphos do Directorio para regimen dos Indios das Aldeias das Capitanias do Pará e Maranhão, approvado por Alvará regio de 17 de agosto de 1758 e que podiam ser applicaveis aos Indios do Estado do Brazil ${ }^{9}$, uma minuciosa análise dos noventa e cinco parágrafos que compõem o Diretório pombalino. Após o proêmio, o texto do Parecer passa a ter uma estrutura regular e repetitiva: apresenta-se uma síntese do conteúdo de cada parágrafo do Diretório pombalino e, a seguir, a posição do Conselho Ultramarino, conforme exemplificamos abaixo:

No paragrafo primeiro do Diretorio se/expoem, que sendo V. Magestade servido pelo Alva-/rá comforsa delei de sete de Junho de mil se-/te centoz esincoenta esinco abolir a adminis-/trasam temporal, que os Regulares exercita=/vaõ nos Indios das Aldeias do Estado do/Maranhaõ ePará mandandoas governar/pelos seos Respetivos Principaes, como estes/pelalastimoza Rusticidade, eignorancia, com/que ategora foraõ educados, não tinhaõ ane-/cessaria aptidão, que se Requer

\footnotetext{
8 A este respeito, consulte-se Marcis (2013, p.148), que diz: "O Parecer enviado para consulta foi severamente criticado por Mendonça Furtado, como se deduz do aviso citado a seguir:

$\mathrm{Na}$ Real Presença de Sua Majestade se fez sumamente repreensível a Carta que o Conde dos Arcos Vice-Rei, e Capitão General, que foi desse Estado dirigiu na data do primeiro de junho de 1759 com o Parecer do Conselho Ultramarino erigido nesta Cidade datado de 19 de maio do dito ano sobre a observância do Diretório, que o Governador e Capitão General do Estado do Grão-Pará e Maranhão formou para o governo dos Índios daquelas capitanias e que o mesmo Senhor mandou praticar com os de seu Estado nas partes aplicáveis.

Porque quando Sua Majestade ordenava se executasse uma Lei qual era o Alvará de 17 de agosto de 1757, que deu força de Lei ao referido Diretório, se mandou fazer junta, sobre a observância da mesma Lei, para invalidar se não reduzir na praxe em que o mesmo Senhor a mandava por: E isto com os superficialíssimos pretextos, que constam do Papel que se fez na mesma Junta.

O que Sua Majestade manda estranhar, ordenando que a referida Lei se de a sua devida execução não obstante os pretextos que no dito Papel se acumularam inconsideradamente."

9 AHU_CU_005-01, Cx. 23, D. 4256.
} 
para oGover=/no, sem que haja quem os posa dirigir, pro=/pondolhes naõ so os meios da civilidade,/mas/mas daconveniencia, epersuadindolhes os/ próprios ditames da Racionalidade, de que vi-/viaõ privados, para que oReferido Alvará ti-/vese asua devida execusam, esse verificassem as/Reaes epiisimas intensoes de V. Magestade, haveri-/a em cadahuã das sobreditas povoasoens, em/quanto os Indios naõ tivessem capacidadepa-/ra se governarem, hum Diretor, que nomeari=/a o Governador, e CapitamGeneral doEstad=/do, oqual deveria ser dotado de bons costu-/mes, zelo, prudência, everdade, siencia dalin-/gua, edetodos os mais Requizitos necessários $\mathrm{pa}-/ \mathrm{ra}$ poder dirigir com acerto os Referidos Indioz/debaxo das ordens edeterminasoens, que/nos parágrafos seguintes haviaõ de declarar-/se, as quaes inviolavelmente se obsrvariaõ,/emquanto V. Magestade assim ohouvese porbem,/enaõ mandáse o contrario.

A Respeito deste primeiro paragrafo: $\mathrm{Pa}$-/rece ao Conselho que seriaõ os Diretores de/que nele setrata muito precisos, emuitou $=/$ teis nasVilas novamente estabelecidas no/distrito desteGoverno para no Regimen delas/ajudarem a civilizar com mais brevidade/aos//aos Indios, porem que sefas impratica-/vel porfalta de pessoas, em que concorram/as qualidades, que essencialmente se Reque-/rem, ou lhes prescreve omesmo paragrafo.

A transcrição do trecho acima teve o propósito não só de exemplificar como se estrutura o texto do Parecer, mas de destacar o fato de o Conselho Ultramarino ter julgado "impraticável" aplicar o que dispõe o parágrafo primeiro - ou seja, a nomeação de um Diretor em cada vila - "por falta de pessoas em que concorram as qualidades que essencialmente se requerem ou lhes prescreve o mesmo parágrafo". A solução encontrada, sem exceção, foi a de delegar todas as funções atribuídas ao Diretor aos escrivães das câmaras dos aldeamentos indígenas elevados a vilas. Contudo, como destaca Cancela (2012, p. 136):

Essa alteração proposta pelos conselheiros não causava nenhuma inflexão nos objetivos centrais do Diretório dos Indios. A atribuição do exercício diretivo para os escrivães assegurava a manutenção da política tutelar, criando as condições de controle da liberdade instituída aos povos indígenas. É certo que a sobrecarga de funções poderia trazer algum tipo de empecilho ao "bom governo" dos índios, uma vez que os escrivães-diretores, além de cumprirem as atribuições típicas do governo e da justiça das vilas, agora teriam que cuidar da civilização dos índios [...]".

No que tange especificamente à civilização dos índios e mais especificamente aos objetivos deste artigo, vejamos, a seguir, o texto do Parecer relativamente aos parágrafos seis, sete e oito do Diretório. Primeiramente, o sexto parágrafo, que dispõe sobre a política linguística:

No paragrafo sexto sededus, que sem- | pre foi máxima inalteravelmente praticada | em todas as nasoens, que conquistáraõ novos | dominios, introduzir logo nos povos conquis- $\mid$ tados o seo proprio idioma, por ser indispu- $\mid$ tavel que este he hum dos meios mais efi- $\mid$ cazes para desterrar dos povos Rusticos a bar- | baridade dos seos antigos costumes, etermos- | trado aexperiencia, que aomesmo paso que | se introdus neles o uso dalingua do Princi- | pe que os conquistou, selhes Radica taõbem | oafeto, aveneraçam, eaobediencia ao mesmo | Principe. Observando pois todas as nasoens | polidas do mundo este prudente, esolido sis- $\mid$ tema, naquela Conquista se praticou tanto | pelo contrario que só cuidáraõ osprimeiros | Conquistadores estabelecer nela ouzo dalin- | gua, que chamaráõ geral ${ }^{10}$; invensam verda- | deiramente abominavel, e diabolica, para | que privados os Indios de todos aqueles meios | que os podiaõ civilizar, permanecesem na Rus- | tica, ebarbara sugeisam, emque ategora se | conservavaõ. Para desterrar este perniciozi- $\mid$ simo abuzo, seráhum dos principaes cuida- $\mid$ dos dos Diretores estabelecer nas suas Res- $\mid$ pectivas povoasoens o uzo da lingua Portugue- $\mid$ za, naõ consintindo por modo algum, que | os meninos, emeninas, que pertencerem as es- $\mid$ colas, etodos aqueles Indios, queforem capa- $\mid$ zes de instrusam nesta materia, uzem da lin- $\mid$ gua propria das suas nasoens, ou da chama- $\mid$ da geral ${ }^{11}$; mas unicamente daPortugueza na $\mid$ forma

10 A palavra "geral" se encontra grafada em destaque, em itálico.

11 A palavra "geral" se encontra grafada em destaque, em itálico. 
queV. Magestade temRecomendado em | Repetidas Ordens, que ategora se naõ obser- | varaõ com total Ruina espiritual, etempo- | ral do Estado.

Parece ao Conselho mandar entre- | gar aosEscrivaens das Camaras Respetivas | a Copia deste paragrafo, paraque eles promo- | vaõ asua observancia nos lugares das suas | Rezidencias".

A seguir, os parágrafos sétimo e oitavo, que se referem ao planejamento linguístico, materializado na determinação quanto à criação de duas escolas públicas que garantissem o sucesso da política linguística pombalina:

\begin{abstract}
Nos parágrafos sétimo, e oitavo se pon- | dera que sendo a determinasamReferida aba- | ze fundamental da civilidade, que se perten- | de haverá em todas as povoasoens duas es- | colas publicas, huã para os meninos, naqual | se lhes ensine a Doutrina Christan, a ler, es- | crever, econtar naforma que se pratica em | todas as Escolas das nasoens civilizadas, e | outra para as meninas, naqual alem de se- | rem instruidas na Doutrina Christan, se | lhes ensinará aler, escrever, fiar, fazer Renda, | custura, etodos os mais ministérios próprios | daquele sexo. Para a subsistencia das so- $\mid$ breditas escolas, edehum mestre, ehuã mes- | tra, que devem ser pesoas dotadas debons cos- | tumes, prudencia, e capacidade, de sorte que | posaõ dezempenhar as importantes obriga- $\mid$ soens de seos empregos se destinaraõ orde- $\mid$ nados suficientes, pagos pelos pais dosmes- $\mid$ mos Indios, ou pelas pesoas, em cujo poder $\mid$ eles viverem, concorrendo cada hum deles | com a porsam, que se lhes arbitrar, ou em di- | nheiro, ou em efeitos, que será sempre com | atensam ágrande mizeria, epobreza, a que eles | prezentemente se achaõ Reduzidos. No cazo | porem de naõ haver nas povoasoens pesoa al- | guã que posa ser mestra de mininas, poderaõ | estas ate aidade de des anos serem instruídas | na escola dos mininos, aonde aprenderaõ a | Doutrina Christan, a ler, e escrever, para | que juntamente com as infaliveis verdadesda | nossa Sagrada Religiaõ adquiraõ com maior | facilidade o uzo dalingua Portugueza.

A Respeito destes paragrafos: Parece | ao Conselho que alem do que neles seacha $\mid$ disposto, se ordene aos Escrivaens da Cama- | ra que continuem no ensino dos meninos | na forma da sua obrigasam, edas meninas $\mid$ da Vila ate aidade de des anos, naõ levan- $\mid$ do estipendio algum de seos pais, ou de outra | pesoa alguã, visto serem satisfeitos pela $\mathrm{Fa}$ - | zendaReal, eque quando pelo tempo adi- | ante suceder serem os Escrivaens Indios, | nese cazo, lhes pagaraõ seos pais, ou as pe- | soas interesadas no ensino.
\end{abstract}

Como já destacado, todas as funções atribuídas ao Diretor são delegadas aos escrivães das câmaras, que se tornam assim, como visto na citação acima extraída de Cancela (2012), escrivães-diretores, passando a caber-lhes, inclusive, o papel de instituir o uso da língua portuguesa nas povoações e, para atingir tal fim, não só que "continuem no ensino dos meninos na forma da sua obrigação", mas que também se ocupem do ensino "das meninas (...) até a idade de dez anos". O uso do verbo continuar revela que, quanto aos meninos índios, o Parecer ratifica uma prática já estabelecida de os escrivães das câmaras os ensinar a ler e escrever, prática que também deveria ser estendida às meninas índias até a idade de dez anos. O escrivão-diretor deveria assumir, portanto, até mesmo as tarefas que antes eram atribuídas ao mestre a à mestra.

\title{
3 O DESCORTINAR DE UMA AGENDA DE PESQUISA
}

Chegamos à parte final deste artigo não apresentando conclusões, mas, antes, apontando para o descortinar de uma agenda de pesquisa em cujo centro estariam os escrivãesdiretores como agentes do ensino de língua portuguesa como segunda língua e do letramento das populações indígenas. Tal agenda deverá buscar responder a questões centrais relativamente à história social linguística do Estado do Brasil, como por exemplo: Em que aldeamentos indígenas alçados, na segunda metade do século XVIII, à condição de vilas foram abertas escolas para meninos e meninas indígenas? Qual o perfil social dos escrivães- 
diretores nomeados? Como atuaram? Quais foram as formas de apropriação da leitura e da escrita pelas populações indígenas nesse período da história colonial e, consequentemente, de sua imersão no complexo mundo da cultura escrita?

Para além dessas questões, vale citar o seguinte trecho de uma entrevista dada por Jean Hébrard à Revista de História da Biblioteca Nacional em 19 de janeiro de 2011, que aponta para a importância de se investigar não apenas os escrivães-diretores, mas o papel exercido pelos escrivães, de forma mais geral, na história da cultura escrita no Brasil:

RH Qual é o foco de interesse das suas pesquisas mais recentes?

JH Comecei a me interessar mais pela questão da escrita do que da leitura. Queria conhecer quem são os profissionais da escrita, como o escrivão na cultura jurídica e administrativa portuguesa. Mas a minha maior motivação vem sendo a seguinte: entender como a cultura da escrita se desenvolve em um país com um índice muito grande de analfabetos. O que significa exatamente escrever no Brasil? Como se dá a formação de uma pessoa que pode escrever na administração, na Justiça, etc.? Esse tipo de pesquisa é muito importante porque ela nos ajuda a entender os nossos arquivos. Para fazer uma boa interpretação de um arquivo, eu preciso entender como ele foi constituído. E, assim, eu acabei me ocupando dos escrivães.

RH O escrivão era uma figura importante no Brasil do século XIX, não é?

JH Com certeza. E bem mais cedo. Não esqueço que a primeira decisão de Colombo, ao chegar nesta ilha do Caribe que pensou serem as Índias, foi chamar o escrivão do navio para registrar a posse do território. E o Cabral fez a mesma coisa quando chegou ao Brasil. Nos impérios ibéricos, havia um escrivão em todos os lugares, na administração, na Justiça, nos cartórios, na polícia... Continuou no Brasil imperial. A cultura do escrivão é absolutamente fantástica. Eu fui ver os tratados de formação dos escrivães. Descobri na Bahia um concurso do século XIX para o recrutamento de escrivães. O juiz responsável pela seleção perguntava: "O que você conhece do Direito? O que conhece da maneira de escrever?" Fiz outro trabalho sobre a cultura dos padres, mais precisamente sobre a maneira como eles redigiam os atos dos registros de batizados, casamentos e óbitos. Cada um tinha uma maneira bem pessoal de fazer o que a Igreja pedia. Numa sociedade onde o que você era no nascimento passava a ser decisivo para a sua posição na vida posterior, é interessante ver como o padre criava uma identidade social, racial e jurídica para cada batizado. Cabia a ele decidir se você era preto ou "sem cor", se você tinha um pai ou não, se você nasceu de uma "Dona" ou de uma fulana. Dependemos muito deste poder da escrita.

\section{REFERÊNCIAS}

ALMEIDA, Maria Regina Celestino de. Os índios na história do Brasil. Rio de Janeiro: Editora FGV, 2010.

ALMEIDA, Rita Heloísa. O Diretório dos índios: um projeto de "civilização" no Brasil do século XVIII. Brasília: Editora Universidade de Brasília, 1997. (Com fac-símile do Diretório dos índios em apêndice).

CALDAS, José Antônio Caldas. Noticia Geral de toda esta Capitania da Babia desde o seu Descobrimento até o prezenta anno de 1759. Editado por Alícia Duhá Lose, Vanilda Salignac de Douza Mazzoni e Perla Peñailillo. Salvador: Memória e Arte, 2015 [1759].

CALVET, Louis-Jean. As políticas linguísticas. Tradução de Isabel de Oliveira Duarte, Jonas Tenfen e Marcos Bagno. São Paulo: Parábola Editorial; IPOL, 2007. 
CANCELA, Francisco Eduardo Torres. De projeto a processo colonial: índios, colonos e autoridades régias na colonização reformista da antiga Capitania de Porto Seguro (17631808). Tese (Doutorado em História) - Faculdade de Filosofia e Ciências Humanas, Universidade Federal da Bahia, Salvador, 2012.

CARNEIRO, Edison. Apresentação. In: VILHENA, Luís dos Santos. A Babia no século XVIII. Bahia: Editôra Itapuã, 1969.

CASTILLO GÓMEZ, Antonio. Historia de la cultura escrita: ideas para el debate. Revista Brasileira de História da Educaşão, Campinas, SP, n. 5, p. 93-124, jan./jun. 2003.

FREIRE, José Ribamar Bessa. Rio Babel: a história das línguas na Amazônia. Rio de Janeiro: EdUERJ; Atlântica, 2004.

HÉBRARD, Jean. http://www.revistadehistoria.com.br/secao/entrevista/jean-hebrard. Acessado em 21 de janeiro de 2017.

LEITE, Yonne; FRANCHETTO, Bruna. 500 anos de línguas indígenas no Brasil. In: CARDOSO, Suzana A. M.; MOTA, Jacyra A.; MATTOS E SILVA, Rosa Virgínia (Org.). Quinhentos anos de história lingüística do Brasil. Salvador: Secretaria da Cultura e Turismo do Estado da Bahia, 2006. p. 15-62.

MARCIS, Teresinha. A integração dos indios como súditos do rei de Portugal: uma análise do projeto, dos autores e da implementação na Capitania de Ilhéus, 1758-1822. Tese (Doutorado em História) - Faculdade de Filosofia e Ciências Humanas, Universidade Federal da Bahia, Salvador, 2013.

MARQUILHAS, Rita (2000). A faculdade das letras: leitura e escrita em Portugal, séc. XVII. Lisboa: Imprensa Nacional - Casa da Moeda.

MORELLO, Rosângela. Política de cooficialização de línguas no Brasil: http://www.youblisher.com/p/611679-RIILP-01-Coloquio-Internacional-deMaputo-Mocambique/

OLIVEIRA, Gilvan Müller de. Brasileiro fala português: monolingüismo e preconceito lingüístico. In: SILVA, Fábio Lopes da; MOURA, Heronides Maurílio de Melo (Org.). O direito à fala: a questão do preconceito lingüístico. Florianópolis: Insular, 2002. p. 83-92.

RODRIGUES, Aryon Dall'Igna. Linguas brasileiras: para o conhecimento das línguas indígenas. São Paulo: Edições Loyola, 1986. 